\title{
Mapping palliative care provision in European prisons: an EAPC Task Force Survey
}

\section{AUTHORS}

Mary Turner ${ }^{1}$, Aline Chassagne ${ }^{2}$, Manuel Luis Capelas ${ }^{3}$, Kenneth Chambaere ${ }^{4}$, Stacey Panozzo $^{5}$, Carla Teves ${ }^{3}$, Edith Riegler ${ }^{6}$ (on behalf of the EAPC Task Force on Palliative Care for Prisoners)

\section{Author affiliations:}

1. School of Human and Health Sciences, University of Huddersfield, Huddersfield, UK.

2. University Hospital, Besancon, France.

3. Universidade Catolica Portuguesa, Institute of Health Sciences, Centre for Interdisciplinary Research in Health (CIS), Portuguese Observatory for Palliative Care (OPCP), Lisboa, Portugal.

4. End-of-Life Care Research Group, Ghent University and Vrije Universiteit Brussel (VUB), Belgium.

5. Palliative Nexus, St Vincent's Hospital and University of Melbourne, Australia.

6. United Nations Office on Drugs and Crime, Vienna, Austria.

\section{Corresponding author:}

Dr Mary Turner

Reader in Health Services Research

School of Human and Health Sciences

University of Huddersfield

Queensgate

Huddersfield

UK

Email: m.turner@hud.ac.uk

Tel: +44 (0) 1484473478

\section{KEY WORDS}

Palliative care

Prisoners

Cross-sectional survey

\section{WORD COUNT}

3,598 words 


\section{ABSTRACT}

\section{Objectives}

Prison populations around the world are ageing and numbers are rising, leading to greater demand for palliative care for prisoners approaching the end of life. This paper reports a survey that was undertaken by the EAPC Task Force on Mapping Palliative Care Provision for Prisoners in Europe. The Task Force was established to begin to address the gap in research knowledge by exploring prison systems and care provision across different countries.

\section{Methods}

The survey, developed by the Task Force Steering Committee, consisted of 40 questions in six sections. It was completed through online searches; only data that were publicly available on the internet were included. Numerical data were analysed using descriptive statistics, and thematic comparisons were made of free text data.

\section{Findings}

The survey was completed for eight countries: Australia, Belgium, Czech Republic, England \& Wales, France, Portugal, Scotland and Slovakia. Three main findings are reported here: healthcare and palliative care provision in prisons; deaths in custody; and compassionate release. Despite increasing numbers of older prisoners, relatively few prisons provide inpatient care, and only one country has any prisons that provide dedicated palliative care services. Early release on compassionate grounds is extremely rare in most countries.

\section{Conclusion}

For the principle of equivalence to be adhered to, facilities for sick and dying prisoners need to be improved, or many more people need to be released on compassionate grounds at the end of life. This mapping study has identified key issues in relation to palliative care in prison, and provides the basis for further international research.

\section{INTRODUCTION}

Prison populations in many countries are growing, in part because of ageing populations but also because of increasingly punitive sentencing policies [1]. Consequently, the numbers of older people in prison, people approaching the end of life, and deaths from natural causes are all increasing. It is also widely acknowledged that the health profile of people in prison is poorer than that of their peers outside; long-term imprisonment causes premature ageing by about 10 years [2]. The combination of these factors means that there is increasing need for palliative and end of life care in prison; it is important to note that human rights legislation (e.g. the Mandela Rules [3]) stipulates that healthcare provided in prison should be equivalent to that provided in the community. However, prisons are designed and built to contain people (predominantly young men) in a secure environment, and often lack the facilities and resources needed by old and dying people; there are also complex ethical issues inherent in keeping frail and vulnerable people in custody. There is therefore a pressing need for research evidence to inform the provision of appropriate care for those who face the end of life in prison. 
Although research into palliative and end of life care in prison is starting to develop in some countries, in others there is little or no evidence, and large gaps in knowledge remain [4]. In the past decade, a few studies have been undertaken, notably in the United Kingdom [5, 6] Switzerland [7,8] and France [9]. In broad terms, research to date has focussed on care for those in prison who require palliative care [6]; the tensions between care and custody [8, 10, 11]; human rights and ethical issues [12], and access to compassionate release [13]. However, in most of Europe there remains a lack of evidence and to date there is no international overview of palliative care provision for prisoners; it is not known for example how many countries have developed any kind of palliative care programme or specialist facilities in prisons. Much of the relevant scientific literature to date is from the United States, where both prison and healthcare systems are based on very different models of provision, making it difficult to draw useful comparisons [14]. Research urgently needs to be developed and shared across countries, in order to share best practices in relation to this important emerging issue, and to implement human-rights based, practical and pragmatic responses to the ageing prisoner crisis.

The issue of early release on compassionate grounds (ERCG) is of particular importance for prisoners approaching the end of life. Different countries have widely differing approaches to ERCG. The International Association for Hospice and Palliative Care (IAHPC) contends that people in prison who are terminally ill, as well as those who have physical or cognitive impairments that require specialist nursing care, should be considered for compassionate release so that they can be cared for in an appropriate setting in the community [15]. Although legal frameworks for ERCG are in place in some countries, research indicates that the number of people released at the end of life is actually very low [1], due to restrictive eligibility criteria, complex and lengthy application processes and the involvement of a plethora of different authorities; however, there currently exists no international overview of policies and practices related to ERCG at the end of life.

In order to begin to address these gaps in research, a Task Force was set up in May 2017 under the auspices of the European Association for Palliative Care (EAPC) to investigate palliative care for people in prison. The original focus was on countries in Europe, but a team of researchers in Australia expressed an interest in joining the project, so Australia was included. The Task Force had two main aims: first, to undertake scoping work in five countries to map the current provision of palliative care for people in prison; and second, to establish an international network of practitioners and researchers with an interest in palliative care in prisons. This paper reports the first phase of the mapping work, a survey to collect data about prisons and prison systems in each of the participating countries, and presents the findings in relation to three key themes: deaths in custody; health and palliative care provision in prisons; and compassionate release.

\section{AIMS AND OBJECTIVES OF THE SURVEY}

The aim of the survey was to provide a description of palliative care in prisons in each participating country, and to make comparisons between countries.

The objectives were: 
- To collect information on prison populations, types and nature of prisons.

- To identify population trends and projections for the next 5-10 years.

- To identify existing healthcare and palliative care services and provision for people in prison approaching the end of life.

- To collect examples of good or innovative practice.

\section{METHODS}

At the start of the project a Task Force Steering Committee was established, initially consisting of six members; as the work developed and more countries became involved, the Steering Committee was expanded to include members from each participating country. Members are from wide-ranging disciplinary backgrounds, including sociologists, health researchers, policy makers, and others. Initially it was proposed that just five countries would take part in the mapping project, as the Steering Committee had limited resources and no funding for this work. However, a pragmatic approach was taken, so other countries that had an identified lead and expressed an interest in participating were also included. Eight countries completed the survey: Australia, Belgium, Czech Republic, England \& Wales, France, Portugal, Scotland and Slovakia. (Although Scotland and England \& Wales are all part of the United Kingdom, they are separate countries with different prison systems, so completed separate surveys.)

\section{The survey tool}

A sub-group of Steering Committee members created a draft survey tool and circulated it to the other members for comment. Further work on the survey took place at the EAPC Congress in Bern, Switzerland, in May 2018, and the final tool was agreed in July 2018. The survey consisted of 40 questions in six sections: types and categories of prisons; prison populations; healthcare in prison; policies and practices; examples of good or innovative practice; and regulatory approvals required for further research in individual prisons (see Appendix A: Survey Tool).

\section{Data collection and analysis}

Steering Committee members in each country took responsibility for collecting the data and completing the survey. Data were collected through online searches of publicly accessible sources; these included government departments of health and justice, prison administrations and prison advocacy organisations. The sources used for each question were recorded (e.g. website addresses), together with the date on which the information was accessed.

The responses from each country were collated for each question in order to facilitate analysis; each question was then analysed in turn. Numerical data were subjected to simple descriptive statistical analysis (the small number of participating countries limited the scope and depth of statistical analysis). For free text data, thematic comparisons were made between different countries as far as possible.

\section{Ethical considerations}


The survey tool sought only information that was already in the public domain, and it was designed to be completed through internet searches. No personal data were sought or collected; therefore, ethical and governance approvals were not required.

\section{FINDINGS}

The survey generated a large amount of data, reported in full elsewhere [16]. Here we present key findings related to three key themes: healthcare and palliative care provision in prisons; deaths in custody; and compassionate release. However, to provide some context for the findings we begin with a brief overview of prisons and prison populations in the participating countries.

\section{Prisons and prison populations}

The number of prisons in each country (excluding immigration detention and removal centres) ranged from 15 in Scotland to 188 in France, but data were not collected about the number of inmates in each prison, the population of each country, or any geographical factors that might impact on the number of prisons required. Although all countries reported having separate institutions for young offenders, there was no evidence of prisons specifically for older people. Prison population rates range from 88 per 100,000 of the population in Belgium to 205 in Czech Republic [17]. All countries segregate prisons by gender apart from France, where most prisons are mixed with male and female units. Males make up the vast majority of prison populations; across all eight countries females accounted for only $5.4 \%$ of all people in prison.

\section{Theme 1: Healthcare and palliative care provision in prisons}

In all eight countries, funding for prison healthcare (including palliative care) is provided by the state. In most countries, the delivery of healthcare is also the responsibility of the state, although in both Australia and England \& Wales a small proportion of healthcare provision is contracted out to private providers. The survey revealed that all prisons in each of the participating countries provide some sort of healthcare (mainly primary care), apart from Portugal, where only 41 of the 55 prisons have healthcare units. The survey asked specific questions about whether or not prisons have in-patient beds, and whether they provide mental health and palliative care as specialist services. Table 1 provides a summary of the responses to these questions. It is interesting to note that there are relatively few prisons with in-patient facilities; this indicates that people in most prisons who need in-patient care have to be transferred to another prison or outside hospital.

Table 1: Types of healthcare services provided in prison

\begin{tabular}{|l|l|l|l|l|l|}
\hline Country & $\begin{array}{l}\text { Total no } \\
\text { of prisons }\end{array}$ & $\begin{array}{l}\text { No of } \\
\text { prisons with } \\
\text { some sort of } \\
\text { healthcare }\end{array}$ & $\begin{array}{l}\text { No of prisons } \\
\text { with in-patient } \\
\text { beds }\end{array}$ & $\begin{array}{l}\text { No of prisons } \\
\text { with specialist } \\
\text { mental health }\end{array}$ & $\begin{array}{l}\text { No of prisons } \\
\text { with dedicated } \\
\text { palliative care }\end{array}$ \\
\hline Australia & 114 & All & $8^{*}$ & All & None \\
\hline Belgium & 35 & All & 2 & 12 & None \\
\hline Czech Republic & 35 & All & $2^{*}$ & All & None \\
\hline
\end{tabular}




\begin{tabular}{|l|l|l|l|l|l|}
\hline England \& Wales & 119 & All & Some* & All & A few* \\
\hline France & 188 & All & 26 & All & None \\
\hline Portugal & 55 & 41 & 8 & 2 & None \\
\hline Scotland & 15 & All & None & All & None \\
\hline Slovakia & 18 & All & 1 & All & None \\
\hline
\end{tabular}

*= exact numbers not known

Dedicated prison palliative care units were reported in only one country (England \& Wales), and only in a few prisons. However, the survey also revealed evidence of recent initiatives to improve care for old and frail prisoners and those approaching the end of life: for example, some prisons in France employ 'life support workers', who go in to help prisoners with their daily needs; and in Scotland, a national project has been initiated to support the implementation of palliative and end of life care standards in all prisons, funded by Macmillan Cancer Support, a national charity.

\section{Theme 2: Deaths in custody}

In order to ascertain the need for palliative care in prisons, the survey asked about the numbers of deaths from natural causes (e.g. heart disease, cancer, respiratory disease) and non-natural causes (suicides and homicides) in the last year for which figures were available. Table 2 summarises these data from seven countries (no recent data were found for Portugal).

Table 2: Deaths from natural and non-natural causes

\begin{tabular}{|l|l|l|l|l|}
\hline Country & No of deaths & Year & $\begin{array}{l}\text { No of natural } \\
\text { cause deaths }\end{array}$ & $\begin{array}{l}\text { No of non-natural } \\
\text { cause deaths }\end{array}$ \\
\hline Australia & 74 & $2016-17$ & 45 & 29 \\
\hline Belgium & 44 & 2017 & 31 & 13 \\
\hline Czech Rep. & 34 & 2017 & 24 & 10 \\
\hline England \& Wales & 310 & $2017-18$ & 173 & 137 \\
\hline France & 168 & 2016 & 62 & 104 \\
\hline Scotland & 26 & 2018 (Jan-Oct) & 9 & 17 \\
\hline Slovakia & 15 & 2018 (Jan-Nov) & 11 & 4 \\
\hline
\end{tabular}

The timeframes for reporting deaths differ between countries, making comparisons difficult. However, it is notable that the number of natural causes deaths in England \& Wales is almost three times higher than the next highest, France.

In three countries there was some evidence of trends in the numbers of deaths in prison. Australia reported a small but steady increase in deaths over 10 years from 0.11 per 100 prisoners in 2005-06 to 0.17 per 100 prisoners in 2014-15. By contrast, both France and Czech Republic reported a small decrease in the overall number of deaths over recent years (10 years in France, 5 years in Czech Republic). In all three countries these trends included deaths from non-natural causes, so the number of natural cause deaths is unclear. However, the survey also collected data about prison population trends and projections (Table 3), which provides clear evidence of increasing older prisoner populations in Australia, Czech Republic, England \& Wales and France; it is likely that such increases in the numbers of older 
people in prison will result in greater numbers of deaths in custody from natural causes in these countries.

Table 3: Prison population trends and projections

\begin{tabular}{|c|c|c|}
\hline Country & Prison population trends & Prison population projections \\
\hline Australia & $\begin{array}{l}\text { Increasing older prisoner population: } \\
\text { - } \quad \text { Age } 50 \text { and over up by } 84 \% \text { from } \\
2,400 \text { in } 2005 \text { to } 4,400 \text { in } 2015 \\
\text { - Age } 65 \text { and over up by } 170 \% \text { from } \\
312 \text { in } 2005 \text { to } 842 \text { in } 2015 \text {. }\end{array}$ & No data available \\
\hline Belgium & $\begin{array}{l}\text { Slight downward trend in total prison } \\
\text { population since } 2013 \text {. }\end{array}$ & No data available \\
\hline Czech Republic & $\begin{array}{l}\text { - } \quad \text { Age under } 18 \text { numbers decreasing } \\
\text { - } \\
\text { Age } 25-45 \text { numbers fluctuating (up } \\
\text { from } 12,853 \text { in } 2015 \text { to } 13,891 \text { in } \\
2016 \text {, and down to } 13,567 \text { in } 2017 \\
\text { - } \quad \text { Age } 50-60 \text { up from } 1,283 \text { in } 2013 \text { to } \\
\text { 2,233 in } 2017 \\
\text { - }\end{array}$ & $\begin{array}{l}\text { In } 2015 \text { the projected growth in total } \\
\text { population was to } 21,740 \text { by } 2024 ; \\
\text { however, by } 2018 \text { the total population had } \\
\text { already reached } 21,804 \text {. }\end{array}$ \\
\hline $\begin{array}{l}\text { England \& } \\
\text { Wales }\end{array}$ & $\begin{array}{l}\text { Increasing older prisoner population: } \\
\text { - } \quad \text { Age } 50 \text { and over up from } 7 \% \text { in } 2002 \\
\text { to } 16 \% \text { in } 2018 .\end{array}$ & $\begin{array}{l}\text { - Total population projected to increase } \\
\text { from } 83,165 \text { in August } 2018 \text { to } 86,400 \\
\text { by March } 2023 \text {. } \\
\text { - Age } 50-59 \text { projected to decrease from } \\
8,607 \text { in June } 2018 \text { to } 8,500 \text { by June } \\
2023 \text {. } \\
\text { - Age } 60-69 \text { projected to rise from } 3,328 \\
\text { in June } 2018 \text { to } 3,600 \text { in June } 2023 \\
\text { - Age } 70+\text { projected to rise from } 1,681 \text { in } \\
\text { June } 2018 \text { to } 2,000 \text { by June } 2023\end{array}$ \\
\hline France & $\begin{array}{l}\text { Increasing older prisoner population: } \\
\text { Age } 50 \text { and over up over the past } 30 \\
\text { years from } 4.5 \% \text { in } 1980 \text { to } 11.8 \% \text { in } \\
2014 \text {. }\end{array}$ & $\begin{array}{l}\text { High projection: } 76,254 \text { by } 2025 \\
\text { Low projection: } 67,137 \text { by } 2025 \\
\text { (Current: } 70,710 \text { ) }\end{array}$ \\
\hline Portugal & No data available & No data available \\
\hline Scotland & The trend appears to be stable. & $\begin{array}{l}\text { Current projections to } 2022-23 \text { suggest the } \\
\text { population will remain stable. }\end{array}$ \\
\hline Slovakia & $\begin{array}{l}\text { Increase in the number of women (no } \\
\text { information about age) }\end{array}$ & No data available \\
\hline
\end{tabular}

\section{Theme 3: Compassionate release}

All countries apart from Portugal and Slovakia reported some sort of legislation or policy relating to ERCG. Where available, compassionate release policies shared some common features, such as needing to consider the nature of the offence(s), the risk of reoffending and the suitability of the non-custodial setting if released. The data also revealed different approaches in relation to whether the release is temporary or permanent. For example, in France the goal is to allow prisoners to obtain optimal treatment under better conditions (i.e. in hospital) and, in the case of terminal illness, to die outside of the prison environment. This means that the majority of people in prison in France are transferred to hospital at the 
end of life. However, rather than release, this is a suspension of their sentence, which means that if they recover they will be returned to prison to serve the remainder of their sentence.

The survey also sought information on the number of requests for compassionate release, and how many of them were granted. Data on compassionate release requests could only be found in three countries; these results are shown in Table 4. It is notable that apart from in France, (where, as explained above, transfer to hospital is achieved through a suspension of the sentence), the numbers of people in prison who are released on compassionate grounds at the end of life is very small.

Table 4: Requests for compassionate release

\begin{tabular}{|l|l|l|}
\hline Country & $\begin{array}{l}\text { Number of applications for } \\
\text { compassionate release }\end{array}$ & Number of applications granted \\
\hline $\begin{array}{l}\text { Czech } \\
\text { Republic }\end{array}$ & $\begin{array}{l}747 \text { prisoners or their kin applied for } \\
\text { a pardon/clemency in 2017. }\end{array}$ & $\begin{array}{l}\text { 2 were pardoned; } 118 \text { had their } \\
\text { sentence suspended for health reasons }\end{array}$ \\
\hline France & $\begin{array}{l}296 \text { requests made between 2002- } \\
2012\end{array}$ & 253 were granted (85\%) \\
\hline Scotland & 5 applications received during 2017 & 2 released \\
\hline
\end{tabular}

\section{DISCUSSION}

This international mapping project has brought together, for the first time, information about palliative care for people in prisons across seven different European countries and Australia, enabling valuable comparisons and insights to be drawn.

In recent years, palliative care services have been developing in many countries $[17,18]$; however, this study provides evidence that there is very little palliative or end of life care currently provided in prisons, and that even the provision of general healthcare in prisons is limited. Although some form of healthcare provision is evident in most or all prisons in each country, the proportion of prisons with in-patient services is small, and it is not known whether and where 24-hour care is provided. There is clear evidence that prison populations are rising across the world [19], and that in many countries the proportion of prisoners (particularly those over the age of 50) with life-limiting conditions, poor health and frailty is also rising, leading to increasing demand for palliative care $[6,10]$. The COVID19 pandemic has also had a disproportionate impact on prisoners, placing further strain on prison healthcare services; one study from the US showed that the COVID-19 case rate for people in prison was 5.5 time higher than that of the rest of the population, and the death rate was also higher [20]. However, our survey shows that there is so far little evidence to be found in the way of specific palliative care provision for people in prison, even in welldeveloped and relatively wealthy countries where palliative care services for the rest of the population are now well established. 
One particularly concerning finding from our survey is that there are no prisons specifically for older people. Prison systems in all the participating countries recognise that young offenders have particular needs and vulnerabilities, so segregate them from the wider prison population and provide specialist services for them. Many older prisoners are also vulnerable, and have multiple and complex health and social care needs, but our survey found no evidence of specialist provision for this age group. There is some anecdotal evidence from England \& Wales of separate units within prisons that have been designated specifically for older people, but these appear to be few and far between and have arisen 'ad hoc' in response to the older prisoner crisis, rather than as part of a strategic response; the level of health and social care they provide is not known. Most older people therefore are housed in mixed accommodation with younger prisoners, in establishments where there may not be suitable facilities and sufficient resources for people with age-related conditions such as frailty, dementia or chronic illness. Prisons in the main were originally designed to hold young men, who have very different needs; the recent rise in the older prisoner population thus presents prison services across Europe and beyond with major challenges in providing appropriate healthcare and palliative care for those in need, especially their older populations.

The study also highlights very different approaches to early release on compassionate grounds in different countries. Only two of the eight participating countries used any form of ERCG frequently, and in both a temporary suspension of the sentence is granted, rather than a permanent release, so if the person recovers they will be recalled to prison. In the other countries it is not used at all or is extremely rare. This is in part because the eligibility criteria for ERCG are often very restrictive; in some countries there is an age threshold, or those serving life sentences are barred from applying; in other countries the person has to be medically assessed as being very close to death before an application can be considered, which often means they die before the application can be processed. There are also bureaucratic hurdles to be overcome; in some countries it must be the person themselves who applies, rather than a relative or case worker, which is difficult or impossible for the very frail or those with cognitive impairments.

The alternative to ERCG, if prisons are to ensure that the principle of equivalence is followed [3], is to provide palliative care 'in house' in prisons. Prisons and prison systems around the world, that have been established for punishment, incapacitation, deterrence and rehabilitation, are not well-suited to providing compassionate care at the end of life, despite the best intentions of some individuals, and it can be argued that prison can never be a suitable place for people to die. Nevertheless, in England \& Wales, designated palliative care units have been developed in a small number of prisons. Typically, they consist of larger cells with sufficient space for a hospital bed, hoist and other equipment, and may also provide facilities for family members who are allowed extended visits. Whilst these units clearly facilitate the provision of high-quality end of life care in prison, they raise questions about equity, because not all people who need them will have access to them. They may also deprive individuals of the opportunity for ERCG, as prison authorities may be less willing to consider this if there is a suitable palliative care unit inside the prison.

Given that in many countries the numbers of old and frail prisoners look set to continue to rise in the foreseeable future, prison services across the world urgently need to either 
provide adequate palliative care in prison or find ways to release dying prisoners so that they can receive appropriate care in the community.

\section{Limitations}

There were some limitations to this study. Due to resource constraints, only eight countries were included in the survey. The amount of data available in the public domain varied widely between countries, and the quality of some of the available data was poor. It is therefore only possible to report what could be found (although the lack of data in some areas can be seen as an important finding in itself). There is also no reliable evidence about the numbers of prisoners in need of palliative care. We found some data about annual numbers of deaths from natural causes, but the number of people in prison with serious life-limiting conditions is probably considerable.

\section{Recommendations}

The study points to a number of recommendations. First, there is a clear need for national and international policies and strategies concerning palliative and end of life care in prison. Options other than custodial sentences (including ERCG) should be considered where appropriate, and where it is not possible to release prisoners at the end of life, policies need to be developed about how best to provide appropriate care in the prison setting, in order to ensure more equitable treatment and care. Second, the resources to care for dying prisoners need to be provided, and staff should receive adequate training and support to enable them to deliver high quality palliative and end of life care. There is further scope for sharing ideas and good practice initiatives for different countries, so it is important to use existing networks and develop new networks to this end. Finally, further research is needed, both national studies where little or no evidence exists, and international studies to explore comparisons; such research needs to include the experiences of key stakeholders. There is also a need to develop appropriate interventions for prisoners with palliative care and end of life care needs, and evaluate the effectiveness and cost effectiveness of these.

\section{CONCLUSION}

This study has provided valuable data for the first stage of the EAPC Task Force on palliative care for prisoners mapping project. It has also shown where there are gaps in data, gaps that in some areas make it difficult to draw comparisons between countries. The numbers of older prisoners are rising in several of the countries that took part in the survey, and these numbers are expected to continue to increase rapidly in the near future. Burgeoning older prisoner populations lead to increased health and social care needs in prison and rising numbers of deaths in custody. The challenges this poses for prison services across Europe and beyond are placing increasing strain on staff and environments, and are unsustainable in the long term.

Failure to provide equivalent care for prisoners approaching the end of life is a violation of human rights principles, so urgently needs to be addressed. There is also an urgent need for further research, using a range of methods, to gather robust evidence in individual countries so that appropriate interventions can be developed and evaluated, and so that comparisons can be made between countries that would allow for the sharing of good practice. The next 
part of the Task Force mapping work will focus on specific prisons in selected countries in order to begin to collect this much-need evidence.

\section{CONTRIBUTORSHIP STATEMENT}

MT and AC planned the work that is reported here; MT, AC, MLC, KC, SP and CT conducted the study. All authors contributed to the reporting of the study, and MT took responsibility for the overall content of this paper.

\section{ACKNOWLEDGEMENTS}

The authors would like to thank the EAPC for its continued support of this work in hosting meetings at EAPC Congresses and publicising the work of the Task Force on its website. We also thank the members of the Task Force Steering Committee for their involvement in and support of this project. We are particularly grateful to Gail Allan, Juliana Bindasova, Olga Bindasova and Steven Vanderstichelen for their help with data collection in Scotland, Czech Republic, Slovakia and Belgium respectively.

\section{REFERENCES}

1. Handtke, V., Bretschneider, W., Elger, B. \& Wangmo, T. (2017). The collision of care and punishment: Ageing prisoners' views on compassionate release. Punishment \& Society 19(1); 5-22.

2. Hayes, A.J., Burns, A., Turnbull, P., Shaw, J.J. (2012). The health and social care needs of older male prisoners. International Journal of Geriatric Psychiatry. https://doi.org/10.1002.gps.3761

3. United Nations General Assembly. (2015). United Nations Standard Minimum Rules for the Treatment of Prisoners (The Nelson Mandela Rules). Available from: https://undocs.org/A/RES/70/175 Accessed 24 July 2020.

4. Stone, K., Papadopoulos, I. \& Kelly, D. (2012). Establishing hospice care for prison populations: An integrative review assessing the UK and USA perspective. Palliative Medicine 26(8); 969-978.

5. Turner, M., Payne, S. \& Barbarachild, Z. (2011). Care or custody? An evaluation of palliative care in prisons in North West England. Palliative Medicine 25(4); 370-377.

6. Turner, M., Peacock, M., Payne, S., Fletcher, A. \& Froggatt, K. (2018). Ageing and dying in the contemporary neoliberal prison system: Exploring the 'double burden' for older prisoners. Social Science \& Medicine 212; 161-167.

7. Handtke, V. \& Wangmo, T. (2014). Ageing prisoners' views on death and dying: Contemplating end-of-life in prison. Journal of Bioethical Inquiry 11(3); 373-386.

8. Marti, I., Hostettler, U. \& Richter, M. (2017). End of life in high-security prisons in Switzerland: Overlapping and blurring of "care" and "custody" as institutional logics. Journal of Correctional Health Care 23(1); 32-42.

9. Pazart, L., Godard-Marceau, A., Chassagne, A., Vivot-Pugin, A., Cretin, E., Amzallag, E., \& Aubry, R. (2018). Prevalence and characteristics of prisoners requiring end-of-life care: $A$ prospective national survey. Palliative Medicine 32(1); 6-16. 
10. Chassagne, A., Godard, A., Cretin, E., Pazart, L., \& Aubrey, R. (2017). The collision of inmate and patient: end-of-life issues in French prisons. Journal of Correctional Health Care 23(1); 66-75.

11. Turner, M. \& Peacock, M. (2017). Palliative care in UK prisons: Practical and emotional challenges for staff and fellow prisoners. Journal of Correctional Health Care 23(1); 5665.

12. Maschi, T. \& Richter, M. (2017). Human rights and dignity behind bars: A reflection on death and dying in world prisons. Journal of Correctional Health Care 23(1); 76-82.

13. Handtke, V., Wangmo, T., Elger, B. \& Bretschneider, W. (2017). New guidance for an old problem: early release for seriously ill and elderly prisoners in Europe. The Prison Journal 97(2); 224-246.

14. Richter, M. \& Hostettler, U. (2017) End of life in prison: Talking across disciplines and across countries. Journal of Correctional Health Care 23(1); 11-19.

15. International Association for Hospice and Palliative Care. (2020). Policy Brief: Compassionate Release: A Practical, Human Rights-Based Approach to the Aging Prisoner Crisis. IAHPC Available from: https://hospicecare.com/uploads/2020/4/Compassionate\%20Release\%20policy\%20brie f.pdf Accessed 24 April 2020.

16. Turner, M., Chassagne, A. et al. (2019). EAPC Task Force: Mapping Palliative Care Provision for Prisoners in Europe: Part A Survey Report. Available from: https://www.eapcnet.eu/Portals/0/PDFs/Part\%20A\%20Survey\%20report\%202019\%20FI NAL\%20amended\%203\%20Feb\%202020.pdf. Accessed 26 March 2020.

17. Wright, M., Wood, J., Lynch, T., \& Clark, D. (2008). Mapping levels of palliative care development: A global view. Journal of Pain and Symptom Management 35(5); 469-485.

18. Loucka, M., Payne, S. \& Brearley, S. (2014). How to measure the international development of palliative care? A critique and discussion of current approaches. Journal of Pain \& Symptom Management 47(1); 154-165.

19. Walmsley, R. (2018). World Prison Population List (Twelfth Edition). Available from: www.prisonstudies.org/sites/default/files/resources/downloads/wppl_12.pdf. Accessed 24 April 2020.

20. Saloner, B., Parish, K. \& Ward, J. (2020). COVID-19 cases and deaths in Federal and State Prisons. JAMA 324(6); 602-603. 